\title{
ВЛИЯНИЕ СИБУТРАМИНА НА ЦЕНТРАЛЬНЫЕ МЕХАНИЗМЫ РЕГУЛЯЦИИ ПИЩЕВОГО ПОВЕДЕНИЯ У ПАЦИЕНТОВ С ОЖИРЕНИЕМ ПО ДАННЫМ ФУНКЦИОНАЛЬНОЙ МАГНИТНО-РЕЗОНАНСНОЙ ТОМОГРАФИИ
}

\author{
'Цветкова Е.С., ${ }^{2}$ Кузнецова П.И., ${ }^{1}$ Романцова Т.И., ${ }^{3}$ Логвинова О.В., ${ }^{3}$ Трошина Е.А., ${ }^{2}$ Кремнева Е.И., \\ ${ }^{2}$ Корнилова А.А.
'ФГАОУ ВО Первый МГМУ им. И.М. Сеченова Минздрава России (Сеченовский Университет), Москва ${ }^{2}$ ФГБНУ «Научный центр неврологии», Москва
${ }^{3}$ ФГБУ «НМИЦ эндокринологии» Минздрава России, Москва

понимание организации нейронных сетей, ответственных за пищевое поведение, и механизмов действия лекарственных средств, влияющих на него, может улучшить эффективность терапии ожирения.

ЦЕЛЬ: оценить изменения пищевого поведения с помощью функциональной магнитно-резонансной томографии (фМРТ) у пациентов с ожирением, которые принимали сибутрамин в течение 3 месяцев.

МАТЕРИАЛЫ И МЕТОДЫ: в Исследование были включены 30 пациентов (из них 86,7\% - 26 женщин), с ожирением, индекс массы тела (ИМТ) $\geq 30$ кг/М². Средний возраст в основной группе составил $31 \pm 7,45$ лет,

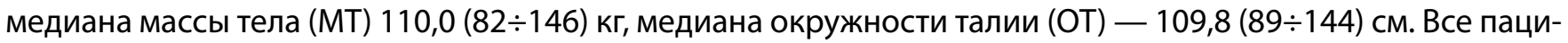
енты были правши. Контрольную группу составили 23 человека с нормальным ИМТ сопоставимого пола и возраста. Все участники прошли первичное МРТ-картирование, сфокусированное на доминантном полушарии головного мозга. Группу ожирения лечили сибутрамином (Редуксин ${ }^{\circledast}$ ) в дозе 10 или 15 мг в день в течение 3 месяцев. После лечения пациенты с ожирением подвергались второму картированию фМРТ для оценки изменений относительно начального картирования.

PЕЗУЛЬТАТЫ: по данным фМРТ в группе с ожирением до лечения отмечалась более низкая активация верхних и нижних теменных долей в обоих полушариях, а также более низкая активация латеральной правой фронтальной коры по сравнению со здоровой контрольной группой. Кроме того, в группе с ожирением также была выраженная активация в области 45, 46 и 9 полей Бродмана в дорсолатеральной префронтальной коре (ДЛПФК) слева. Активация дополнительной моторной области (ДМО) и ДЛПФК справа у пациентов с ожирением отсутствовала по сравнению с контрольной группой. Через 3 месяца лечения сибутрамином у $80 \%$ пациентов произошло значимое ( $\geq 5 \%)$ снижение МТ. Медиана снижения МТ соста-

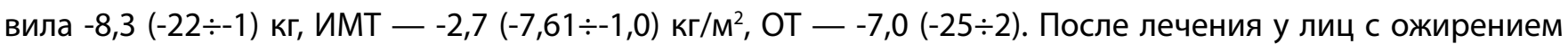
наблюдалось уменьшение активации зрительной коры, ДЛПФК и появление активации в области 8 поля Бродмана слева.

ВЫВОДЫ: ДЛПФК и ДМО являются важными частями нейронной сети, контролирующей пищевое поведение. Согласно наблюдениям, полученным при фМРТ в этом исследовании, пациенты с ожирением, получавшие сибутрамин в течение 3 месяцев, показали снижение активации в проекции левой ДлПФК, что было расценено как изменение нарушенных паттернов питания и может указывать на усиление контроля аппетита в результате проведенного лечения.

КЛЮЧЕВЫЕ СЛОВА: оЖИрение; пищевое поведение; фМРТ; сибутрамин 